\section{A Rare Case of Hodgkin's Lymphoma in Accessory Spleen}

\section{Abstract}

Accessory spleen (AS) is a congenital focus of healthy splenic tissue that is separated from the main body of the spleen. It is a frequently normal variant that is found in up to $30 \%$ of cases at autopsy examination. According to literature, it is usually an incidental finding because it is assymptomatic. It might even be confused as a lymph node on CT scan. It is thought that most accessory spleens are tiny and incapable of pathogenic activity. Hodgkin lymphoma (HL) exclusively in the accessory spleen has been seldom reported in the literature. We report a rare case of a HIV positive man with Classic Hodgkin lymphoma in accessory spleen, with B symptoms, positive markers and positive Epstein Barr Virus (EBV) LMP. He showed symptomatic and laboratory improvement on antiretroviral therapy and was referred for ABVD with outpatient follow up.

Received: January 12, 2017; Accepted: January 18, 2017; Published: January 25, 2017

\section{Introduction}

Patients with HIV have an 8-fold increased risk of Hodgkin lymphoma compared with the general population [1-3]. While the incidence of more AIDS defining cancers has declined, the incidence of $\mathrm{HL}$ in AIDS has increased, possibly due to the use of combination antiretroviral [4,5] and therefore improved immunity. Patients with HIV on treatment are still at an increased risk however compared with the general population. Nearly all cases in individuals with HIV are associated with Epstein Barr Virus (70-80\%), B symptoms and histologically, half of cases are mixed cellularity [6] as seen in our patient below.

\section{Case Report}

A 51 year old Nigerian male with a past medical history of HIV on Lamivudine, nevirapine, zidovudine and tenofovir presented to the SJEH Emergency with complaints of abdominal pain, generalized weakness, jaundice, fever, bone pains, loose bowel stools and progressive weight loss for the last 2 years. He was initially worked up in Nigeria, but he was referred to India and Dubai where a bone marrow biopsy revealed hypo cellular bone marrow with fibrosis and plasmacytosis. His brother had died of Tuberculosis. He was found to be HIV positive with a CD4 count of 233. He was started on HAART but discontinued medications. He had previously declined to reveal his HIV status. With no improvement, he decided to seek more definitive work up in the USA.

\section{Odianosen Obadan, Raymond Pastore, Deborah Schron and Obiora Anyoku}

\author{
St. John's Episcopal Hospital, far Rockaway, \\ New York, USA
}

\section{Corresponding author: \\ Odianosen Obadan \\ odiaobadan@yahoo.com}

St. John's Episcopal Hospital, far Rockaway, New York, USA.

Tel: $X X X X X X X X X X X$
Citation: Obadan O, Pastore R, Schron D, et al. A Rare Case of Hodgkin's Lymphoma in Accessory Spleen. J Intensive \& Crit Care 2017, 3:1.

There was no history of IV drug use or use of hepatotoxic substances. In SJEH, lab tests revealed a platelet count of 13,000 Hgb of 7.9, Hct of 22.7, WBC count of 2.2, elevated liver enzymes and coagulation profile. Hepatitis and Malaria parasite tests were negative. Abdominal ultrasound revealed hepatomegaly, accessory spleen and gall stones. Abdominopelvic CT scan confirmed the presence of accessory spleen. HIV positive with CD4 counts 235 and 153 twice, with undetectable viral loads on both occasions. Patient's mental status deteriorated. A lumbar puncture was negative. He underwent surgery. The liver and spleen were normal. Pathology of accessory spleen showed Classical Hodgkin lymphoma, mixed cellularity type, reticulin positive, CD15 +ve, CD30 +ve, Fascin +ve, MUM-1 +ve, PAX 5 $+v e$, Epstein Barr Virus LMP positive in atypical cells. His HIV was treated with Raltegravir and Emtricitabine/Tenofovir. Mental status improved on treatment, with liver enzymes trending down. He was supported with blood products and vitamin $\mathrm{K}$ for anemia and coagulation abnormalities. The patient's relative and the patient wanted to be treated in an Oncology Center in Manhattan where he was treated with ABVD. He did well on treatment and was discharged home from the Oncology Center in NYC and was followed as an outpatient. 


\section{Strategy}

Literature review search was conducted using NCBI and PubMed databases from Jan 20 to July 2016. Key words used were Hodgkin's, Lymphoma and Accessory Spleen. We searched articles in English but we were not able to find articles with Hodgkin's lymphoma in an accessory spleen (Figures 1-3).

\section{Discussion}

Hodgkin's Lymhoma outside of HIV is a disease characterized by a bimodal age distribution with an initial peak at age 20-30 and a second peak at age 50-65 while the median age of HL presentation in HIV is in the 30 s after a median time from HIV diagnosis of approximately $71 / 2$ years $[6,7]$. The median CD4 count at $\mathrm{HL}$ diagnosis is approximately 240 cells/ $\mu \mathrm{L}$ [6]. The CD4

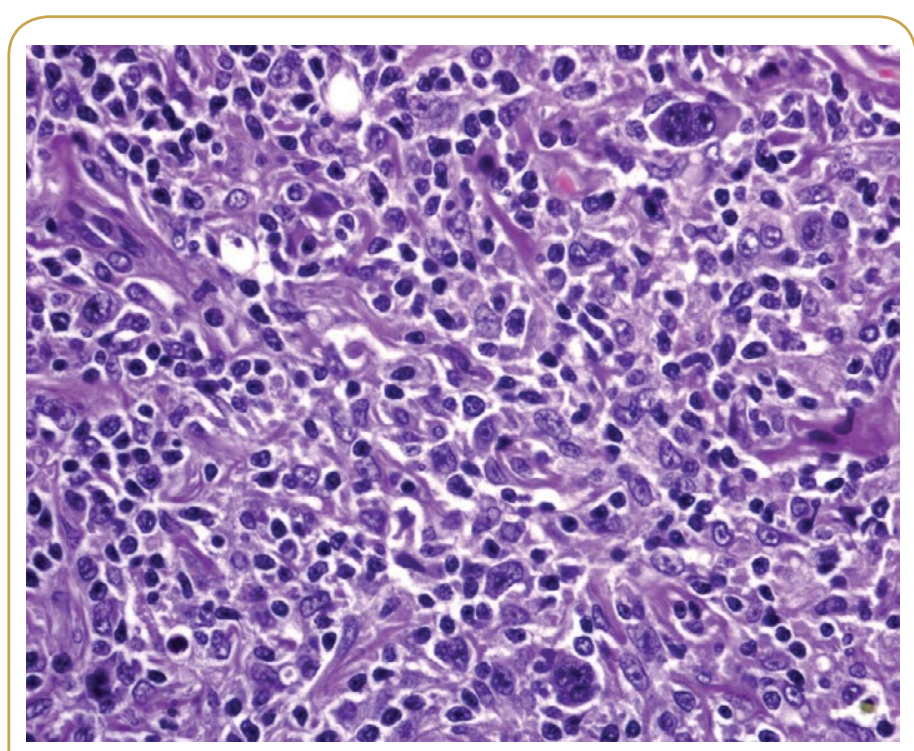

Figure 1 Reed Stenberg cell.

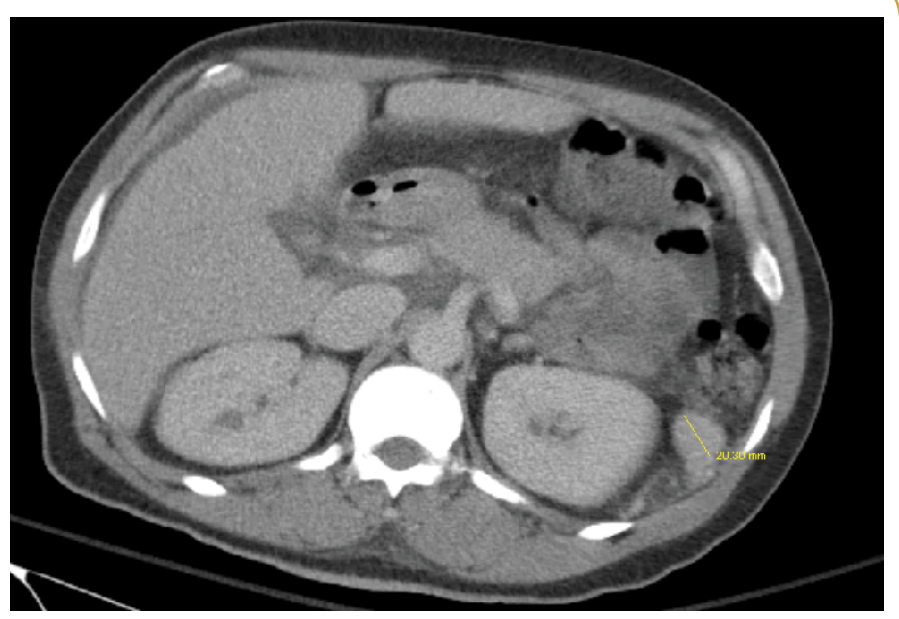

Figure 2 CAT scan.

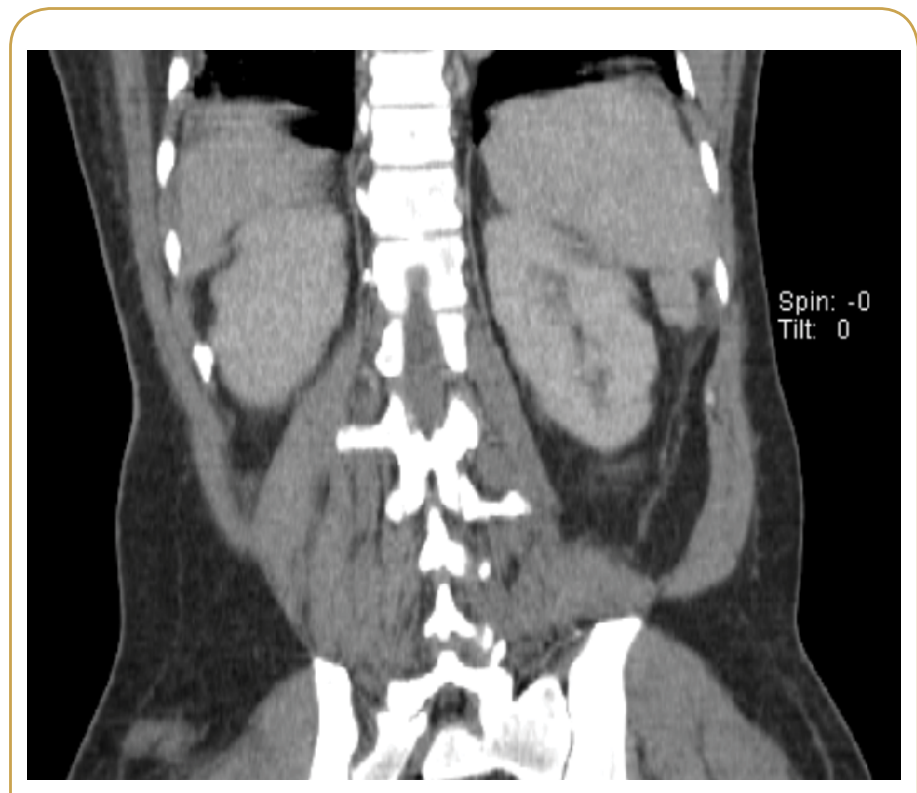

Figure 3 Ultrasound.

count in our patient was 235 and then 153 which was close to the median count in other studies above.

The introduction of antiretroviral therapy has led to people resenting with more early stage disease and the standard of therapy is chemotherapy.

It is suggested that EBV is an important etiological factor in the development of HIV associated HL $[3,4]$. This patient's lymphoma in the accessory spleen was an incidental finding. He had elevated liver enzymes and hepatomegaly, elevated INR and other coagulopathy (had to be given Plasma products to support him), pancytopenia. The decision was made to do a liver biopsy because of coagulopathy and elevated liver enzymes. Also to look at the accessory spleen seen on ultrasound. A biopsy of the liver and also a biopsy of the accessory spleen were taken during the procedure with the above results. This shows that the possibility of an accessory spleen as an extra nodal site should be taken seriously. Our patient had a normal spleen. The disease was only seen in the accessory spleen and presented with vey symptomatic disease. Also, more studies need to be done for better therapies for HIV patients with Hodgkin's because of the possible multiple etiologies and poor prognosis.

\section{Conclusion}

Hodgkin's lymphoma is a very rare condition, most times, presenting with nonspecific "B" symptoms. Most times it presents as lymph node enlargement. It also presents as a splenic mass. A thorough clinical examination and investigation are necessary to rule out the disease in other organs, including an accessory spleen which could also present with B symptoms and serious illness as seen in this case above. Chemotherapy is still the treatment of choice. 


\section{References}

1 David G, Hanna B, Natalia G, Dorit S, Jacob S (2010) Accessory spleen-like masses in oncology patients: Are they always benign? World J Radiol 2: 368-373.

2 William HC (1972) Splenectomy in hematologic disorders. N Engl J Med 286: 252-1254.

3 Carbone A, Gloghini A, Serraino D, Spina M (2009) HIV-associated Hodgkin lymphoma 4: 3-10.

4 Karuanayake M, Adair C (2009) HIV associated lymphoma. Proc Bayl Univ Med Cent 22: 74-76.
5 Lawrence DK (2012) Management of HIV-associated Hodgkin lymphoma: How far we have come. J Clin Oncol 30: 4056-4058.

6 Caron AJ, Jeremy SA (2012) HIV-Associated Hodgkin's Iymphoma: Prognosis and therapy in the era of combined cART. Adv Hematol 2012: 507257.

7 Ja KK, Jee SH, Gwi EK, Woo-Ick Y (2005) Three cases of diffuse large B-cell lymphoma presenting as primary splenic lymphoma. Yonsei Med J 46: 703-709. 